\title{
Health Care Rationing and Professional Autonomy: The Case of Cardiac Care in Ontario
}

\author{
Lydia Kapiriri ${ }^{*}$, , Glen E. Randall ${ }^{2}$ and Douglas K. Martin ${ }^{3}$ \\ ${ }^{I}$ Department of Health, Ageing and Society, McMaster University, 1280 Main Street West, Hamilton, Ontario, L8S 4M4, \\ Canada \\ ${ }^{2}$ Health Services Management Program, DeGroote School of Business, McMaster University, 1280 Main Street West, \\ Hamilton, Ontario, L8S 4M4, Canada \\ ${ }^{3}$ Department of Health Policy, Management and Evaluation and the Joint Centre for Bioethics, University of Toronto, \\ 88 College Street, Toronto, Ontario, M5G 1L4, Canada
}

\begin{abstract}
The purpose of this paper is to explore how rationing decisions are made by government and hospital policy makers and practitioners, at the micro, meso and macro levels of analysis, through examining the rationing of cardiac care in a Canadian hospital, and discussing how the interaction between policy makers and practitioners at each of these levels affects the process and outcomes. Data were collected through in-depth interviews with 20 key informants. We found that decision-making for rationing cardiac care is a complex process. As government and hospital policy makers seek to control costs through greater oversight of clinical decisions, practitioners resist this perceived challenge to their autonomy. Attempts by policy makers at the macro and meso levels to standardize the rationing process have had limited success as practitioners have largely retained their ability to make independent rationing judgments at the micro level. This study underscores the difficulties associated with efforts to constrain the autonomy of practitioners in making "bedside rationing" decisions and the need to move towards a more collaborative model of clinical governance.
\end{abstract}

Keywords: Bedside rationing, cardiac care, clinical governance, health policy, priority setting, professional autonomy.

\section{INTRODUCTION}

A persistent problem, which faces all publicly funded health care systems, is the seemingly endless demand for resources due to an aging population, the use of increasingly expensive drugs and technology, and a more demanding public. Since frontline health care professionals determine what services patients' access, they have been partly blamed for the escalating health budgets. It is commonly argued that practitioners' flexible, inefficient and possibly inequitable, approach to rationing health care at the bedside has contributed to the escalating costs of the health care system [1]. Failure to either improve efficiency or constrain demand can only lead to additional pressures to ration health care [1, 2]. One of the key challenges governments face is rationing health services in a manner that is effective, efficient, and is perceived by the public to be fair and equitable.

The purpose of this paper is to explore how policy makers and practitioners make rationing decisions at the micro, meso and macro levels and to describe the factors that ultimately influence the rationing of cardiac care through an examination of the rationing of cardiac care in one large urban Ontario, Canada hospital. The paper will begin by providing a definition of rationing and some background about the Canadian health care system as contextual background to the study. It will then describe the rationing

*Address correspondence to this author at the Department of Health, Ageing and Society, McMaster University, 1280 Main Street West, Hamilton, Ontario, L8S 4M4, Canada; E-mail: kapirir@mcmaster.ca process for cardiac care and elaborate on the main factors that affect rationing decisions. The paper then concludes with a discussion of how the interaction among government and hospital policy makers and practitioners shapes the decision-making process and outcomes. Gaining a better understanding of the interaction that takes place among government and hospital policy makers and practitioners in making rationing decisions will serve to inform collective efforts to improve priority-setting processes in cardiac care, as well as for other services and other contexts.

\section{Rationing Health Care}

Rationing may be any mechanism which limits access to health care services at the different levels of the health care system $[1,3]$. Rationing may be implicit, whereby neither the decisions nor the reasons are clearly expressed, or explicit, with policies and their rationale made open and transparent [4]. Traditionally, government and hospital policy makers have been reluctant to make explicit rationing decisions [5], preferring instead to ration care at the macro level through limits on global budgets, at the meso level through limits on specific hospital resources (such as number of beds), or at the micro level by leaving individual patient care decisions to practitioners at the bedside [6-8]. However, as treatment for many conditions such as cardiac care utilize increasingly expensive technology and the demand for services continues to grow, so has the pressure to find more acceptable ways to ration care. Controlling cost through blunt instruments such as limiting global budgets or number of hospital beds have had limited impact. At the same time, 
practitioners' autonomy in making rationing decisions at the micro level has come under increasing scrutiny and even criticism due to a growing perception that this rationing approach is neither efficient nor fair [9-11].

Rationing, by physicians at the micro level, poses an ethical dilemma for practitioners since they are expected to play a dual role as both advocate for their patients and gate keeper for society at large [3, 4, 12]. However, physicians have been found to favour their patient advocate role over the societal role. Consequently, some governments and hospital policy makers have attempted to gain greater oversight of clinical decisions through a variety of mechanisms [13-15]. Such bureaucratic controls have been perceived, by some, as infringements on the physicians' professional autonomy [16].

One particular example where the provision of care has been a challenge and often subject to rationing is the delivery of cardiac care. The complexity, high cost of the technology, urgency, and the human emotion associated with the provision of cardiac care make it a priority setting challenge in all health care systems.

\section{Canadian Health Care System}

Health care in Canada falls primarily under the jurisdiction of its provincial governments and is more accurately described as a collection of ten provincial health care systems. The extent to which each provincial system resembles one another is largely in response to the provinces' efforts to qualify under the Canada Health Act for federal funding towards their programs and services [17]. Canada has a publically funded universal health insurance program, referred to a Medicare, which provides citizens and permanent residents, in all provinces, with access to "medically necessary" hospital and physician services. The Canada Health Act allows services, which are not provided by physicians or in hospitals and are not deemed "medically necessary", to be provided on a for-profit basis.

In Ontario, the vast majority of hospitals are private, notfor-profit organizations that operate primarily with provincial government funding. As private organizations, hospitals in Ontario have enjoyed significant independence from government. It has only been in that past couple of years that the provincial government has required hospital executives to sign accountability agreements that clarifies what services will be provided to local communities in exchange for provincial government funding. Likewise, physicians have historically functioned as independent practitioners who operate with substantial independence from both the hospitals where they provide services, and the provincial government which provides the funding for those services. While in recent years more complex blended physician funding models have increased in popularity, most physicians are still paid directly through the province's insurance program on a fee-for-service basis [17].

The relative independence that hospitals have from the provincial government and that physicians have from hospitals increases the complexity of the decision-making process for determining which patients receive clinical services and in which order. This also leads to a blurring of the lines of accountability for the decisions made.

\section{Rationing Cardiac Care in Ontario}

In the province of Ontario, Canada, the challenges associated with the delivery and rationing of cardiac care have contributed to cardiac services being identified as a "priority" area beginning in 2002. This means that cardiac services are now funded separately from other health care services according to government imposed guidelines to which hospitals are required to adhere. These guidelines provide individual hospitals with clear direction in terms of the type and number cardiac surgical procedures that are permitted and will be funded by the government. This is a dramatic departure from past government policy where no such limits were placed on hospitals.

In addition, the province's Cardiac Care Network (CCNO) has developed guidelines and a rating system for allocating patients who require cardiac services to waiting lists [18]. The CCNOs rating system is based on a medical need model in which an "Urgency Rating Score" (URS) is calculated for each patient, and patients are prioritised according to their score. The URS for cardiac surgery includes weighted values of variables such as the severity of the patient's condition, stability of symptoms of angina, coronary anatomy, non- invasive test for risk of ischaemia, left ventricular function and presence of co-morbidities (including peripheral vascicular disease, cerebrovascicular disease, chronic obstructive pulmonary disease, diabetes, congestive cardiac failure) $[18,19]$. The URS score is intended to restrict non-medical factors from influencing the priority ranking given to patients who require cardiac surgery. Within hospitals, practitioners are expected to adhere to the URS prioritization of patients, without further modification unless there has been a change in the patient's medical condition. In this context, it may be reasonable to ask to what extent practitioners continue to retain the autonomy to make rationing decisions at the bedside.

There is a growing body of literature on bedside rationing by practitioners [7-11, 19, 20]. Most of this literature describes the criteria used by practitioners to ration health care, with an underlying emphasis on practitioners' reluctance to ration care. Some of the literature also highlights physicians' lack of compliance with the formal CCNO guidelines and the "tension between the expectations of administrative bodies [to use less resources] and the reality of the necessity of resources to operate on the population of patients", as an issue that has not been well examined in the literature. In part, it is this identified gap that this paper seeks to fill.

\section{METHODS}

Data for this qualitative case study comes primarily from a series of in-depth key informant interviews. Respondents were recruited from the provincial government, the Cardiac Care Network of Ontario (CCNO), and a large tertiary-care urban teaching hospital in Ontario, Canada. Face-to-face interviews were conducted between January and October 2005 , using an interview guide that had been pre-tested. The interview guide dealt broadly with decision-making and the rationing of cardiac care. It covered topics such as: who participated in decision-making process; which issues were considered; and how the decision-making process could be improved. 
Respondents were identified using a combination of theoretical and snowball sampling [21]. The index respondent, who was the Chief Executive Officer of the hospital, identified subsequent respondents who were who the heads of the various clinical and support programs related to cardiac care in the hospital. Those participants identified subsequent respondents who they perceived to be key individuals who were knowledgeable about the funding and delivery of cardiac care services either within the hospital or throughout the province. A total of 20 respondents including: six cardiac surgeons and cardiologists; three non-physician clinical staff ( two nurse managers in charge of the Operating Room (OR) and one in charge of the Intensive Care Unit (ICU)) ; one representative from the CCNO; four representatives from the hospital's senior management; and four representatives from the provincial government.

Interviews were recorded (with permission from the respondents) and transcribed. The transcripts were then analysed using a modified thematic analysis process whereby the transcripts were read and key concepts identified. The key concepts were then grouped together under overarching themes. Any emerging concept that related to the major concept of rationing in cardiac care was also followed-up, analyzed and are reported below as dimensions of the central theme [22].

Research ethics approval for this study was obtained from both the University of Toronto Office for Research involving Human Subjects and the study hospital's Research Ethics Committee. Prior to the interview, respondents signed a written consent form.

\section{RESULTS}

The results section is organized according to the major themes which emerged from the data, namely: (i) the need to ration cardiac care; (ii) key rationing factors considered (at the micro-level, at the meso-level and at the macro-level); and (iii) standardising rationing decisions.

\section{The Need to Ration Cardiac Care}

Most of our respondents (physicians and policy makers at the meso and macro levels) recognised the need to ration cardiac care. The physician respondents (cardiologists and cardiac practitioners) reported that the level of resources (especially the human resources and infrastructure) devoted to cardiac care has been insufficient which has contributed to long wait times for cardiac procedures. One cardiac surgeon noted that it generally took patients $2-3$ months to get scheduled for elective care. He further noted that:

\footnotetext{
Waiting list management is a huge issue in Canada right now. There are numerous efforts to look at how we do things ... sometimes the resource allocation may not be sufficient to deal with the waiting lists.... It may be on a service basis but also it could be on an individual basis.
}

Several of the physician respondents also expressed concern that the demand for cardiac services could be expected to grow as the average age of the population increases together with the related cardiac problems. They advocated for more resources to deal with the increasing demand.

The provincial government and hospital administrator respondents also readily acknowledged the resource shortage, but rather than viewing the solution as simply persuading government to provide more resources they tended to stress the need to attempt to allocate the available resources in both an efficient and fair manner. In fact, these respondents generally viewed practitioners as impediments to achieving these goals since, in their view; practitioners were too focused on individual patients rather than the system as a whole. One administrator highlighted this view, noting that:

$$
\begin{aligned}
& \text {... it's interesting that ... when you create policy } \\
& \text { around rationing and prioritisation, a lot of } \\
& \text { people are not inclined to participate in the } \\
& \text { process. ... Doctors philosophically don't feel } \\
& \text { they should be part of the rationing process } \\
& \text { because their mandate is to provide the best } \\
& \text { carefor an individual [patient]. }
\end{aligned}
$$

Of course, not all practitioners expressed this view. Some clearly appreciated the necessity to consider other factors besides the needs of an individual patient. One physician noted that, "we have an ethical and moral responsibility to consider the broader public good along with our individual contract with an individual patient." Recognising that the health budget is finite, both clinical and non-clinical respondents agreed that there was need to improve the priority setting process given the growing demand for cardiac services.

\section{Key Rationing Factors Considered at the Micro Level}

Physician respondents identified several factors they considered when rationing cardiac care including; professional and clinical judgement, patient related values and personal preferences. We present these in detail.

Physicians indicated that when using their professional judgment in making rationing decisions, the most common criterion they used in determining which patients to prioritise for medical investigations or surgical procedures was medical need / necessity. Respondents noted that practitioners must consider physical need in terms pain, suffering, and risk to life and urgency. For example, changes to a patient's clinical condition can sometimes lead to an emergency, which typically receives priority over routinely scheduled patients. According to respondents, scheduled (non-emergency) cardiac patients are to be prioritised on the waiting list on a first come first serve basis. However, should a patient's condition deteriorate while waiting for care, he or she may be able to jump the queue which would necessitate the re-scheduling of the other patients. While most practitioners thought this was reasonable, some felt that this causes systematic marginalising of patients with less urgent conditions, whereas they also forfeit a lot to prepare for their procedures. As noted by a physician respondent:

\footnotetext{
... the concept that elective patients are deferrable without harm $t$ is not true. Patients ... having major surgery go through a lot of effort to plan time from work, help at home, care for children, care for dependants, elderly,
} 
whatever. There's a lot of social consideration of what a patient goes through.

Another factor that influenced practitioners' decisions was the extent to which a patient may benefit. Patients who are most likely to benefit from treatment are given priority. One surgeon described patients who are unlikely to survive or those that have much co-morbidity as receiving low priority while those with a more optimistic prognosis receiving "high priority."

Despite the appearance that medical factors drive practitioners' decision-making, the reality is that nonmedical or personal factors also play an important, and perhaps even decisive, role in the decision-making process. Personal factors deal with the values, preferences, and interests of individual practitioners who provide care and make clinical decisions at the bedside. While respondents were generally reluctant to discuss the extent to which nonmedical or personal factors played a role in decision-making, they confirmed that non-medical factors are often considered.

A typical example was the physician's perception of how much an individual patient deserves to receive care. For example, some respondents indicated that a patient's age, independent of his or her medical condition, can be a factor that influences decision-making. While one physician respondent argued that age is not a major factor in their decision making, other physician respondents suggested that age may in fact play an important role. It was argued by some, particularly in cases of equal urgency, that the patient's age may be considered and priority could be given to the younger patient. This suggests that there may be an unspoken bias against elderly patients when it comes to the delivery of cardiac care.

Some physician respondents justified their use of age as a criterion by tying it to a patient's ability to benefit from care and to subsequently return to normal or pre-morbid functioning. One respondent explained the situation this way:
It's more than their biologic age, I guess. So, if you are 80 and you behave like 70 that's a little bit different than if you are 60 behaving like 80 . It's hard to assign points and everyone has their own way of doing it...so age does make a difference... if they were healthy, walking their dog, and relatively healthy before and they suddenly get sick, then the probability of being successful and returning to that pre-morbid condition, is very high, so that patient receives a high priority.

Another physician respondent indicated that priority might be given to patients who are self-employed, and therefore unable to support their family due to a lack of income. He noted that "... if the patient is unemployed - no income ... isn't able to work because of their disease process ... then that sometimes plays a role in the decision-making".

Likewise, it was noted by several respondents that, in some instances, individuals identified as "very important persons" (VIPs) and professional colleagues have traditionally been given priority that might not have been warranted by their medical condition alone.

With regards to personal preferences, physicians noted that patients or their families and friends, who make a lot of noise and put pressure on the medical professionals or incite fear of litigation, might also have a faster intervention than those who simply wait their turn.

Furthermore, practitioner's respondents indicated that the kind of surgeries a surgeon commonly performs affects patients' wait time. First, practitioners who handle complex cases requiring long operating time have a limited number of patients they can fit within their allocated operating room (OR) time. Second, popular practitioners have longer waiting lists due to their patients' unwillingness to be treated by other practitioners. However, OR availability is influenced by factors beyond the control of practitioners.

\section{Key Rationing Factors Considered at the Meso Level}

Meso level respondents identified several factors that they consider which impact rationing of cardiac care at the micro level. These included; limiting access to the OR and ICU beds, support for the URS guidelines, human resource availability, competing hospital needs and the general hospital policies.

OR time allocation is done within the limits stipulated by the provincial government; however, the criteria used for allocating OR time between practitioners were not well articulated by the respondents. The primary goal of the allocation is for the hospital to meet the provincial targets. While the OR in the facility under investigation is open twenty-four hours a day, most of the time there is competition for the limited space available. Interview respondents described a situation in which most practitioners are demanding more OR time due to long waiting lists for patients who require care for both acute and chronic conditions.

Meso level managers also influence micro level decisions by determining the number of ICU beds available to cardiac patients. Many patients undergoing cardiac care will require an ICU bed for a variable period of time. Hence, limited availability of ICU beds sometimes leads to some surgeries being cancelled and then re-scheduled. Respondents noted that it is common to find that patients who require long-term care occupy more than half of the ICU beds. Moreover, there has been an increase in patients that require isolation, which further limits the availability of physical space and beds. These factors impact directly on the number of new postoperative patients that can be accepted into the ICU. A hospital manager respondent noted that a patient "may be scheduled for a certain day. But when the day actually comes, then there's more priority setting done, we may not have a physical bed."

Another factor that is considered is the availability of staff. One hospital manager respondent noted that, "we may not have the staff to safely care for patients postoperatively." Another respondent noted that, "if there's shortage of anaesthetists or nursing [staff] ... then I cancel cases based on their percentage of scheduled block time". In an effort to use resources as efficiently as possible, hospitals must also be concerned with how unionised staff is scheduled. For 
instance, staff must be paid for a minimum of four hours regardless of the length of an operation or procedure. Likewise, overtime may be required for longer surgeries. In order to optimise scheduling, operations which are too short or too long are sometimes re-scheduled. In some rare instances, due to lack of support staff, an OR may have to be closed and this means cancellation of surgeries. Here, efforts are made to make sure that they cancel operations for patients who are least likely to have adverse effects.

In addition to assessing the priority of cardiac patients, hospitals must also take into consideration the priority of other (non-cardiac) patients who may need to access the ORs. A physician respondent complained that:

\begin{abstract}
...Now you have medicine patients crowding our emergency rooms. The only flexibility the hospital has is scheduled surgical care. And a lot of people said, those patients should have priority. To heck with scheduled care ... the first priority would be patients in the emergency room, and then patients who need surgical care in a scheduled way would be unfairly discriminated against because those medical patients would take all the beds.
\end{abstract}

\section{Key Rationing Factors Considered at the Macro Level}

In this study we found that government policy makers limit hospital funding for cardiac surgeries to a pre-set number of procedures. Hospitals commit to use the funding to meet the specified targets and if they fail, they are technically obligated to send back the money. Since the provincial government provides the bulk of the funding, macro level policy makers also influence the number of ORs, ICU beds and the staffing levels for each hospital. Macro level decision maker respondents reported that they use epidemiological information to estimate and project the need for each hospital, depending on the demographics of the catchment population. This then forms the basis for determining the provincial priorities, number of "necessary" cardiac procedures (which hospitals must report on in order to justify their budget expenditures) and resource allocation to the hospitals. The macro level respondents also reported that they supported the CCNO and the use of the URS as a tool for micro-level rationing.

Table 1 summarises the factors that are considered at the micro, meso, and macro levels.

\section{Standardising Rationing Decisions}

Policies that impact rationing decisions at the bedside are often intertwined with policies set at the organisational or government levels. In our study, policy makers at both the government and hospital levels have implemented policies designed to standardise the decision-making process with respect to rationing cardiac care. At the provincial level, the Ontario government has moved towards standardisation by identifying cardiac care as a priority program within the province and by supporting the implementation of a rating system to standardise prioritisation through the CCNO. The routine process is for a triage nurse to review the patient's referral and evaluate the patient's status according to the URS, and then allocate them to the next available time on the waiting lists for individual practitioners. The practitioners should then re-assess each patient, also using the URS tool and also notify the CCNO regional coordinator.

At the same time, the hospital OR developed an internal triage system, which also focuses on medical need as the main criterion for prioritising patients for cardiac care, to complement the CCNO system. The hospital triage system was developed by nurses, clinical leaders, managers and practitioners responsible for cardiac care. A manager noted that:

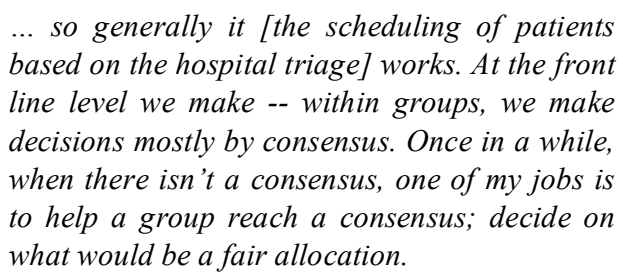
based on the hospital triage] works. At the front line level we make -- within groups, we make decisions mostly by consensus. Once in a while, when there isn't a consensus, one of my jobs is to help a group reach a consensus; decide on what would be a fair allocation.

The hospital triage process was seen as a mechanism for providing both managers and practitioners within the hospital with greater control over decision-making. However, despite several physician respondents indicating that their rationing decisions were guided by both the URS and the hospital's triage policy, they also made it clear that their individual professional opinion and personal values continued to play a role. Several other physician respondents gave both the URS and the hospital triage policy an even lower level of importance in making their rationing decisions. Physicians were able to "game" the system and alter the priority of their patients by a combination of attempting to classify some patients as more urgent than an objective assessment might otherwise warrant or by simply ignoring the URS rating and hospital policy. One of the practitioners justified his behaviour in disregarding the URS process and hospital triage policy by noting that these guidelines did not address all situations and that even if they did, it would be difficult to apply such criteria consistently without systematic marginalising certain groups of patients (such as those whose conditions are not urgent).

The practitioners believed that standardisation was needed for others in the system, but that they should have ultimate rationing authority due to their professional expertise. Consequently, there is no standard cardiac care rationing process. One surgeon noted that, "it takes a lot of wisdom and balance, because there are no rules; we've tried. There's just no way to write a set of rules." Another surgeon respondent confirmed this, noting that, "I mean the whole premise of the URS is to prevent that [inequitable access] from happening but it does."

\section{DISCUSSION}

In the results section, we presented; (i) our respondents' recognition of the need to ration cardiac care, (ii) the key factors that influence rationing of cardiac care at the micro, meso and macro levels, and (iii) some of the attempts made by the macro and meso level planners to standardise rationing of cardiac care.

While a few respondents expressed reluctance to ration cardiac care, most of our respondents recognised the need to ration cardiac care because they recognised the insufficiency of the level of resources available for cardiac care. These findings, are consistent with the literature [1, 2, 4, 9, 23-25]. 
Table 1. Factors Considered when Making Ration Decisions for Cardiac Care

\begin{tabular}{|c|c|c|}
\hline $\begin{array}{l}\text { Main Factors Considered by Practitioners } \\
\text { (at the Mirco Level) }\end{array}$ & $\begin{array}{l}\text { Main Factors Considered by Hospital Policy Makers } \\
\text { (at the Meso Level) }\end{array}$ & $\begin{array}{l}\text { Main Factors Considered by Provincial } \\
\text { Policy Makers (at the Macro Level) }\end{array}$ \\
\hline $\begin{array}{cl}\text { Professional/Clinical Judgement } \\
\text { - } & \text { Need } \\
\text { - } & \text { Urgency } \\
\text { - } & \text { Ability to benefit } \\
\text { Patient related Values } \\
\text { - } \quad \text { First-come-first-serve philosophy } \\
\text { - } \quad \text { Patient age } \\
\text { - } \quad \text { Patient social status (VIPs and } \\
\text { - } \quad \text { Polleagues) } \\
\text { Patient employment status } \\
\text { Personal Preferences } \\
\text { - } \quad \text { OR time allocated } \\
\text { - } \quad \text { Other pressures (e.g. demanding } \\
\end{array}$ & $\begin{array}{ll}\text { - } & \text { Competing needs of other departments } \\
\text { - } & \text { ICU bed availability } \\
\text { - } & \text { OR time availability } \\
\text { - } & \text { Human resource availability } \\
\text { - } & \text { Hospital policies on prioritisation } \\
\text { - } & \text { Support for URS guidelines }\end{array}$ & $\begin{array}{ll}\text { - } & \text { Resource allocation to hospitals } \\
\text { - } & \text { Provincial priorities and targets } \\
\text { - } & \text { Support for URS guidelines }\end{array}$ \\
\hline
\end{tabular}

The factors that influence rationing of cardiac care were also consistent with some of the literature on criteria for rationing access to care [23-25]. Physicians' approaches permit the use of criteria such as patients' age and social status which are considered to be unacceptable, since they may introduce unjustifiable inequities in access to health care [19, 26-29]. Moreover, there is a stark contrast between factors considered by physicians that focus on individual patients, and factors considered by policy makers that focus on institutional constraints (Table 1). To reconcile the differences between the practitioners' and the policy makers' considerations, and in an effort to "improve" the rationing process, policy makers have attempted to standardise practitioners' approach to rationing. At the macro level, the provincial government has attempted to standardise the practitioners' approach to rationing by providing guidelines with regards to the number of procedures that would be funded for each hospital and supporting the development of the URS triage system. At the meso level, policy makers attempted to implement the URS system as well as their own hospital specific triage policy.

Despite the availability of standardised guidelines, we found poor compliance, which is consistent with findings documented elsewhere in regard to both cardiac care [19] and critical care [27]. Our practitioner respondents expressed mixed responses to standardising decision-making. Some supported the idea though they suggest that standardisation tools should be followed by other people, while they themselves continue to make decisions based on an idiosyncratic set of both clinical and non-clinical factors which may sometimes mean ignoring the URS ratings as well as internal hospital policies. Others have been more overt and vocal in their opposition to any perceived constraints on their autonomy. Practitioner autonomy is generally justified by their possessing a defined body of knowledge which forms the foundation for their clinical judgments [24, 30,31]. Overall, our study suggests that cardiac practitioners have been successful in resisting perceived challenges to their autonomy as demonstrated by the failure of government and hospital level policy makers to fully enforce either the URS system or internal hospital policies.

Lack of compliance with standardised guidelines has been associated with limited involvement of the front-line implementers in the process of the guideline development. Guidelines that are developed through a transparent and participatory process, involving all the relevant stakeholders have greater legitimacy and more acceptable to those individuals who are expected to implement them [6]. In our study, while some clinician experts were involved in the development of the URS, there was a lack of vocal ownership of the guidelines by the clinicians. This may partly explain the lack of compliance with the guidelines, emphasizing the need to improve mutual understanding and involvement of the different professional groups responsible for rationing at the different levels in developing the guidelines.

However, participation should not only be limited to the development of guidelines, but should also be facilitated in clinical governance. All relevant stakeholders should either be involved in or have access to the decisions and the rationales used in decision making on rationing in cardiac carte at the various levels. This would improve the legitimacy of the whole process [32]. At the micro level, the factors considered or rationales in rationing should be made explicit, publicized and discussed so as to develop an acceptable set of acceptable criteria. While the URS should be integral to these discussions; here the discussion should focus on encouraging more buy-in by the practitioners who should also be given an opportunity to add any other criteria they may consider as relevant. These discussions should inform the development of guidelines at the subsequent levels. At the meso level, there is also need to embrace some participatory mechanisms in developing their guidelines, whereby there is clear consideration of factors raised by stakeholders at the micro level. Furthermore, while it is 
impractical to directly involve all stakeholders, at the minimum, relevant stakeholders should have access to the criteria and rationales used (in ensuring the rationing of cardiac care ) at this level. Decision makers at this level should also seek feedback with regards to the usefulness of their tools, from the frontline implementers. At the macro level, rationing decisions should seek input from all relevant stakeholders, including patients, practitioners and policy makers. The roles of each stakeholder should be explicit to ensure shared responsibility in the rationing process [25, 32]. The participation of patients would ensure consideration of their values, which is important because they use and pay for the services (through taxes, insurance premiums or out of pocket); while participation of practitioners in the development of policies and guidelines would encourage their compliance. Such wide participation and transparency at all levels of decision making would foster understanding, and improve public accountability, legitimacy and acceptance of the rationing guidelines.

\section{LIMITATIONS}

This study represents a snapshot in time within the context of one Canadian province and one hospital within the province. The structural relationship that exists between the provincial government, hospitals and practitioners in Ontario will be distinct from relationships found in other jurisdictions. In addition, this small qualitative study considers the decision-making process in one Ontario hospital. Hence, and the findings cannot be easily extrapolated to other countries or even other provinces. However, generalizability was not our aim. The aim of the study was to understand how rationing decisions are made within the study context.

The study focuses on demand-side reasons for increasing expenditure on health. While providers have been identified as the main cost-drivers, focusing on only the providers' perceptions creates an incomplete picture. However, focusing on the all aspects that may impact rationing was beyond the scope of our study.

\section{CONCLUSIONS}

Our results reveal that decision-making for rationing cardiac care is a complex process highlighted by the interaction, and growing tension, among government policy makers, hospital policy makers, and practitioners. As government and hospital policy makers seek to control costs through greater oversight of clinical decisions, practitioners resist this perceived challenge to their autonomy. While government and hospital policy makers may have a shared goal of cost control their views and broader interests are not monolithic. In fact, they may at times be divergent. It appears that it is this lack of coordinated mission that contributes to the mutual inability to constrain clinical practice at the bedside. As a result, attempts by policy makers to standardise the rationing process have had limited success as practitioners have largely retained their ability to make independent rationing judgments, which may contribute to some degree of inequality for Canadian patients.

This study demonstrates that the decision-making process for rationing cardiac care is complex and subject to a combination of institutional, professional and personal influences. It highlights the difficulties associated with attempting to standardise the rationing process by constraining the autonomy of practitioners and their ability to make independent rationing decisions despite efforts to implement guidelines designed to standardise decisionmaking. This is not meant to suggest that unfettered physician autonomy is necessarily in the best interest of the health care system but rather that failing to take into consideration the broader context within which power struggles occur will inevitably result in the failure of any policy which challenges physician control. If efforts to standardise the rationing process in a way that is perceived by the public to be fair are to be successfully implemented, then the responsibility for rationing care should not be conceived of as either the role of policy makers or practitioners, but rather as a collective decision that involves different actors at the different levels of the health care system. This suggests the need to move towards a more collaborative model of clinical governance in which relevant stakeholders are involved in developing guidelines for rationing cardiac care, the criteria used is made explicit and the rationing process at all levels is transparent. This may help reduce the tension between the policy makers and practitioners which is the real road block to standardizing the rationing of cardiac care.

\section{ACKNOWLEDGEMENTS}

The study was funded in part by the Canadian Institute for Health Research through the Canadian Priority Setting Research Network. We also acknowledge the hospital management for allowing us to conduct the study and our respondents for having taken time out of their busy schedules to participate in this study.

\section{REFERENCES}

[1] Asch DA, Ubel PA. Rationing by any other name. N Engl J Med 1997; 336 (23): 1668-71.

[2] Ham C, Coulter A. International experience of rationing (or priority setting). In The Global Challenge of Health Care Rationing, Coulter A, Ham C, Eds. Philadelphia: Open University Press 2000; pp. 1-12.

[3] Ubel PA. Rationing Health care, not all definitions are created equal. Arch Intern Med 1998; 158: 209-14.

[4] Mechanic D. Dilemmas in rationing health care services: the case for implicit rationing. Br Med J 1995; 310: 1655-7.

[5] Hughes D, Griffiths L. But if you look at the coronary anatomy: Risk and rationing in cardiac care. Sociol Health Ill 1996; 8(2): 172-97.

[6] Norheim OF. Healthcare rationing - are additional criteria needed for assessing evidence based clinical practice guidelines? Br Med J 1999; 319: 1426-9.

[7] Tasnim S, Kamyar K, Deborah CJ, Luce J, Mitchell M. For the Values, Ethics and Rationing in Critical Care (VERRICC) Task Force. Rationing critical care beds: a systematic review. Crit Care Med 2004; 32(7): 1588-97.

[8] Simms M. Opening the black box of rationing care in later life: the case of 'community care' in Britain. J Aging Health 2003; 15(4): 713-37.

[9] Graber MA, Tansey JF. Autonomy, consent, and limiting health care costs. J Med Ethics 2005; 31(7): 424-6.

[10] Morreim EH. 1995. Balancing Act: The New Medical Ethics of Medicine's New Economics. Washington, D.C.: Georgetown University Press 1995.

[11] Carlsen B, Norheim OF. "Saying no is no easy matter" - a qualitative study of competing concerns in rationing decisions in general practice. BMC Health Serv Res 2005; 5: 70. 
[12] Levinsky NG. The doctor's master. N Engl J Med 1984; 311: 15735.

[13] Dent M. Patient choice and medicine in health care: Responsibilization, governance and proto-professionalization. Public Manage Rev 2006; 8(3): 449-62.

[14] Kitchener M, Caronna CA, Shortell SM. From the doctor's workshop to the iron care? Evolving modes of physician control in US health systems. Soc Sci Med 2005; 60(6): 1311-22.

[15] Germov J. Managerialism in the Australian public health sector: towards the hyper-rationalization of professional bureaucracies. Sociol Health Ill 2005; 27(6): 238-758.

[16] Zuger A. Dissatisfaction with medical practice. N Engl J Med 2004; 350: 69-75.

[17] Dentsky AS, Naylor D. Canada's health care system - reform delayed. New Engl J Med 2003, 349(8): 804-10.

[18] CCNO (Cardiac Care Network of Ontario). Monitoring Performance, Managing Access, Moving Waiting Times. Toronto: CCNO: Annual Report 2006.

[19] Walton NA, Martin DK, Peter EH, Pringle DM, Singer PA. Priority setting and cardiac care: a qualitative case study. Health Policy 2007; 80(3): 444-58.

[20] Kapiriri L, Martin DK. Bedside rationing by health practitioners: a case study in a Ugandan hospital. Med Decis Making 2007; 27(1): 44-52.

[21] Kvåle S. Interviews, An Introduction to Qualitative Research Interviewing. Thousand oaks: Sage Publications 1999.

[22] Strauss A, Corbin J. Basics of Qualitative Research. Techniques and procedures for developing grounded theory. California: Sage Publications 1998 .
[23] Norheim OF. Limiting access to allogeneic bone marrow transplantation in five European countries: what can we learn about implicit rationing? Health Policy 2000; 52(3): 149-56.

[24] Ridderstolpe L, Cllste G, Rutberg H, Ahlfeldt H. Priority setting in cardiac care: a survey of decision making and ethical issues. J Med Ethics 2003; 29: 353-8.

[25] Shufelt K, Chong A, Alter DA. Triage for coronary artery bypass graft surgery in Canada: Do patients agree on who should come first? BMC Health Serv Res 2007; 7: 118

[26] Kapiriri L, Norheim OF. Criteria for priority setting in health care in Uganda: exploration of stakeholders' values. Bull World Health Organ 2004; 82: 172-9.

[27] Mielke J, Martin DK, Singer PA. priority setting in critical care: a qualitative case study. Crit Care Med 2003; 31: 2764-8.

[28] Huang J, Zhou S, Groome P, Tyldesley S, Zhang-Solomans J, Mackillop WJ. Factors affecting the use of palliative radiotherapy in Ontario. J Clin Oncol 2001; 19: 137-44.

[29] Kisely S, Cox M, Smith M, Lawrence D, Maaten S. Does inequitable access to cardiological or neurological procedures contribute to preventable mortality in people with mental illness?" Can Med Assoc J 2007; 176: 779-84

[30] Freidson E. The Profession of Medicine: A Study in the Sociology of Applied Knowledge. New York: Harper and Row 1970.

[31] Dupuis HM. Professional autonomy: a stumbling block for good medical practice. An analysis and interpretation. Theor Med 2000; 21(5): 493-502.

[32] Martin DK, Abelson J, Singer PA. "Participation in health care priority setting through the eyes of the participants." J Health Serv Res Policy 2002; 7: 222-9.

(C) Kapiriri et al.; Licensee Bentham Open.

This is an open access article licensed under the terms of the Creative Commons Attribution Non-Commercial License (http://creativecommons.org/licenses/by$\mathrm{nc} / 3.0 /$ )/ which permits unrestricted, non-commercial use, distribution and reproduction in any medium, provided the work is properly cited. 